\title{
Contrast echocardiographic assessment of the neonatal ductus arteriosus
}

\author{
D B KNIGHT AND V Y H YU \\ Department of Paediatrics, Queen Victoria Medical Centre, Melbourne, Victoria, Australia
}

SUMMARY Contrast echocardiography is a safe and accurate method of diagnosing patent ductus arteriosus (PDA) in newborn infants. In this study the presence of PDA in very low birthweight infants receiving mechanical ventilation was investigated by contrast echocardiography. This was used as a basis for determining the accuracy of clinical signs and $\mathrm{M}$ mode echocardiography in the diagnosis of PDA. At the first contrast echocardiographic examination at a mean age of 49 hours PDA was found in $75 \%$ of infants. Clinical signs were inconsistent; $42 \%$ of the infants with PDA at the first examination had a murmur, no relation being found between PDA and heart rate or cardiothoracic ratio. Left atrial and left ventricular dimensions were significantly raised and left systolic time intervals significantly lower in the group with PDA. There was, however, considerable overlap, with the sensitivity of each measurement varying between $52 \%$ and $71 \%$. Left systolic time interval combined with left ventricular:aortic root ratio gives the best differentiation between infants with or without PDA.

Accurate assessment and early treatment of patent ductus arteriosus (PDA) has an important role in the management of preterm infants with respiratory disease. It has been reported that those with early development of a left to right shunt had worsening clinical condition, which improved after ablation of the shunt. ${ }^{1}$ In controlled studies infants undergoing early closure of the PDA had significantly reduced occurrence of bronchopulmonary dysplasia or mortality, ${ }^{2}$ decreased duration of treatment with oxygen and fewer days necessary to regain birth weight,${ }^{3}$ and lower rates of pneumothorax and retrolental fibroplasia. ${ }^{4}$ At the same time data have been accumulating on the inadequacies of conventional clinical and $M$ mode assessment of PDA. ${ }^{5-9}$ Up to $74 \%$ of infants with documented PDA had no clinical murmur, and normal echocardiographic dimensions and systolic time intervals have been reported in the presence of PDA.

Contrast echocardiography, either with the suprasternal notch or the left parasternal view, has been shown to be a sensitive, safe, repeatable, and accurate method of documenting PDA. ${ }^{6-8}$ In this study the presence of PDA in a group of mechanically ventilated very low birthweight infants was diagnosed by contrast echocardiography to determine the accuracy of clinical and $M$ mode assessment of PDA.

\section{Patients and methods}

Infants with a birth weight of $1500 \mathrm{~g}$ or less who were receiving mechanical ventilation were selected for serial contrast and $M$ mode echocardiographic studies. Fifty three studies were carried out in 17 patients. All had umbilical arterial catheters in situ with tips positioned between $\mathrm{T} 5$ and $\mathrm{T} 9$, for use in the contrast echocardiographic study. Their mean (SD) birth weight was 1107 (286) $\mathrm{g}$ with a range of $580-1500 \mathrm{~g}$, and the mean (SD) gestational age was $27.8(2 \cdot 5)$ weeks with a range of 23 to 31 weeks. All had hyaline membrane disease except one who had group B streptococcal pneumonia. The initial examination was carried out at a mean (SD) age of 49 $(5 \cdot 6)$ hours with a range of $42-62$ hours. Clinical evaluation preceded echocardiographic study on all occasions. Infants were examined for the presence of a systolic murmur maximal at the left sternal edge or below the left clavicle or a continuous murmur, with bounding pulses. The heart rate and cardiothoracic ratio on chest $x$ ray film were also ascertained for correlation with contrast echocardiographic assessment of PDA.

Echocardiography was performed using an Advanced Technology Laboratories Mark 60) ultrasound system, which comprised an 86 ()C Imager, a 51D echo-analyser, and a 5 or 7.5 Megahertz 
transducer. Recordings were made from the suprasternal notch, visualising the transverse aortic arch and right pulmonary artery. ${ }^{6}$ Additional recordings were made of the left parasternal view of the pulmonary valve. ${ }^{8}$ Recordings were graded as 'positive' if the right pulmonary artery filled or 'negative' if only the transverse aortic arch filled. Between 0.5 and $1 \mathrm{ml}$ of $5 \%$ dextrose solution was injected. Peripheral venous injections were performed to confirm the identity of the right pulmonary artery and to document right to left shunts.

$M$ mode echocardiograms were recorded and measured according to the recommendations of the American Society of Echocardiography ${ }^{10}$ using leading edge echos. Systolic time intervals were measured according to the method of Hirschfeld et al. ${ }^{11}$ The isovolumic contraction time was calculated by subtracting the interval from the $Q$ wave to mitral valve closure from the pre-ejection period at similar heart rates. Measurements were made to an accuracy of $5 \mathrm{msec}$.

Statistical analysis was carried out using Fisher's

Table 1 Clinical data on infants with and without patent ductus arteriosus at first study. Values are mean $(S D)$

\begin{tabular}{|c|c|c|}
\hline & $\begin{array}{l}\text { Infants with } \\
\text { patent ductus } \\
\text { arteriosus } \\
(n=I 2)\end{array}$ & $\begin{array}{l}\text { Infants without } \\
\text { patent ductus } \\
\text { arteriosus } \\
(n=4)\end{array}$ \\
\hline Birth weight (g) & $11(17 \quad(288)$ & $110.5 \quad(.309)$ \\
\hline Gestational age (wk) & $27 \cdot 9(2 \cdot 6)$ & $27 \cdot 4(2 \cdot 4)$ \\
\hline Apgar score at five minutes & $7 \cdot 5(1 \cdot 2)$ & $7 \cdot 5(1 \cdot())$ \\
\hline Highest fractional inspiratory oxygen & $0.67(0.18)$ & $0.59(0.21)$ \\
\hline $\begin{array}{l}\text { Lowest arterial partial pressure of } \\
\text { oxygen: fractional inspiratory oxygen } \\
\text { ratio }\end{array}$ & $94 \quad(47)$ & $120 \quad(7.3)$ \\
\hline $\begin{array}{l}\text { Highest mean airway pressure } \\
\qquad\left(\mathrm{cm} \mathrm{H}_{2} \mathrm{O}\right)\end{array}$ & $12 \cdot 8(2 \cdot 7)$ & $12 \cdot 2(3 \cdot 8)$ \\
\hline Fluid intake ( $\mathrm{ml} / \mathrm{kg} /$ day $)$ & $127 \quad(64)$ & $124 \quad(26)$ \\
\hline
\end{tabular}

In first 48 hours. exact test to determine the difference between groups and the Mann-Whitney U test. Only the first recording of an infant or the first recording after a change in contrast pattern was used for statistical comparison of echodimensions and timing. The study was approved by the ethics in medical research committee of the Queen Victoria Medical Centre.

\section{Results}

Satisfactory recordings were obtained from 49 of 53 echocardiograms. On three occasions no contrast was visualised, and one recording was technically unsatisfactory. Duct patency was documented on 35 occasions. A PDA was present in $12(75 \%)$ of 16 infants (one initial study unsatisfactory) on the initial contrast echocardiographic examination. There was no significant difference in birth weight, gestational age, Apgar scores, severity of respiratory distress, and fluid intake over the first 48 hours between infants with and without PDA (Table 1).

At the time of the first examination seven $(58 \%)$ of the 12 infants with PDA did not have a murmur. Overall, no murmur was heard in $23(66 \%)$ of the 35 examinations in which a PDA was documented. None of the infants without a PDA on contrast study had a murmur. There was no significant correlation between the presence of a PDA and the heart rate or cardiothoracic ratio on chest $x$ ray film.

Left ventricular end diastolic dimension and left atrial dimensions were significantly raised and left systolic time intervals (left pre-ejection period/left ventricular ejection time (PEP/LVET)) were significantly lower in infants with PDA (Table 2). The left isovolumic contraction time and left isovolumic contraction time:left ventricular end diastolic dimension ratio were also significantly lower in the presence of PDA. There was considerable overlap, however, of the echocardiographic indices in infants with and those without PDA (Fig. 1) and the

Table 2 Echocardiographic variables in infants with and without patent ductus arteriosus. Values are mean (SD)

\begin{tabular}{|c|c|c|c|c|}
\hline & $\begin{array}{l}\text { Infants with patent } \\
\text { ductus arteriosus }\end{array}$ & $\begin{array}{l}\text { Infants without patent } \\
\text { ductus arteriosus }\end{array}$ & p Value & Sensitivity $(\%)$ \\
\hline $\mathrm{LA}(\mathrm{mm})$ & $8.9 \quad(2.4)$ & $6 \cdot 8 \quad(0 \cdot 8)$ & $<0 \cdot(05$ & 61 \\
\hline LA:AO & $1.59 \quad(0.54)$ & $1.05(0.18)$ & $<0) \cdot(0)$ & 58 \\
\hline LVED $(\mathrm{mm})$ & $12 \cdot 8 \quad(1 \cdot 6)$ & $10.6 \quad(0.9)$ & $<0 \cdot(x) 1$ & 64 \\
\hline LV:Ao & $2 \cdot 24 \quad(0.38)$ & $1 \cdot 6.3(0.23)$ & $<0 \cdot(x) 1$ & 52 \\
\hline LPEP/LVET & $0.28 \quad(0.06)$ & $0.42(0.06)$ & $<0) \cdot(x) 1$ & 56 \\
\hline LICT (msec) & $20.9 \quad(11.7)$ & $42 \cdot() \quad(9 \cdot(1)$ & $<() \cdot())$ & 71 \\
\hline LICT/LVET & $0 \cdot 10 \quad(0 \cdot 06)$ & $(0.22(0.07)$ & $<(0 \cdot 0) 1$ & 67 \\
\hline
\end{tabular}

Sensitivity $=\frac{\text { Positive }}{\text { Positive }+ \text { Negative }} \times 1(0) \%$

LA=left atrial dimensions: LA:Ao=left atrial:aortic ratio: LVED=left ventricular end diastolic dimension: LV:Ao=left ventricular:aortic ratio: PEP/LVET=left pre-ejection period/left ventricular ejection time: L.ICT=left isovolumic contraction time: LICT/LVET=left systolic time interval (left isovolumic contraction time/left ventricular ejection time). 


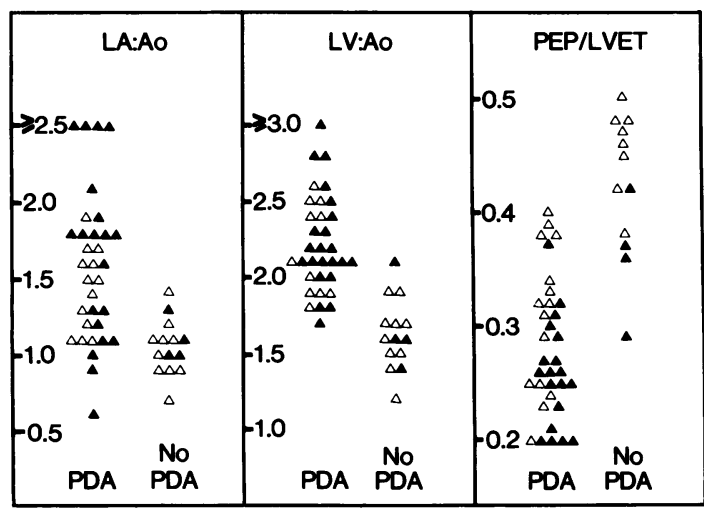

Fig. 1 mode measurements for infants with (PDA) and without (No PDA) patent ductus arteriosus. $\triangle$ First value or value after a change in contrast pattern, $\Delta$ repeat echocardiograms.

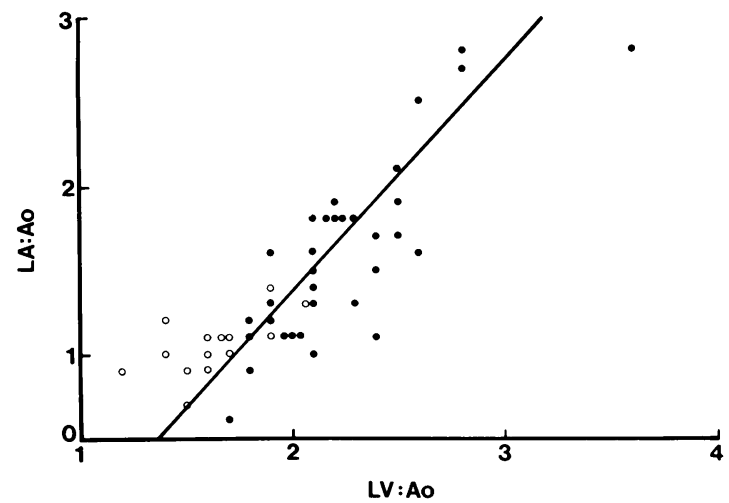

Fig. 2 Left atrial:aortic ratio ( $L A: A o)$ plotted against left ventricular:aortic ratio $(L V: A o) .=$ Infants with patent ductus arteriosus, $\mathrm{O}=$ infants without patent ductus arteriosus $(n=47, r=0 \cdot 84)$.

sensitivity of each variable varied between $52 \%$ and $71 \%$. There was a significant correlation between the left atrial:aortic and left ventricular:aortic ratios (Fig. 2) and a negative correlation between PEP/ LVET and left ventricular:aortic ratio (Fig. 3) or left atrial:aortic ratio (Fig. 4).

\section{Discussion}

Contrast echocardiography is a sensitive method of detecting shunts in the newborn and is useful in detecting right to left shunts with venous injections ${ }^{12}$

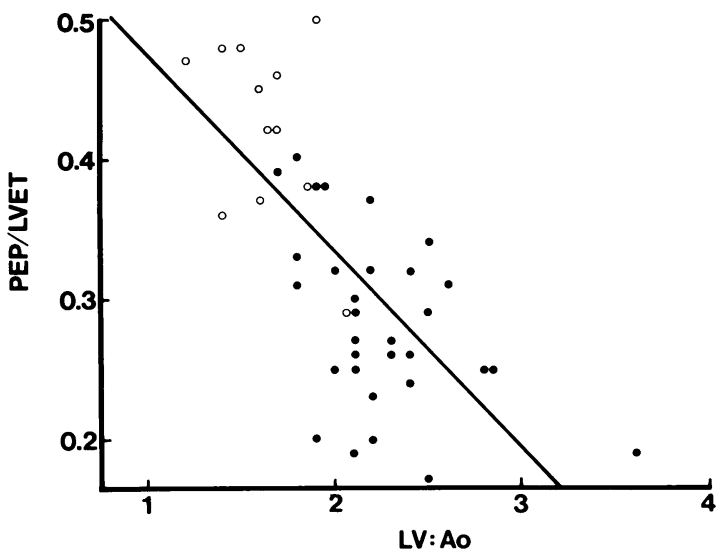

Fig. 3 Left pre-ejection period/left ventricular ejection time (PEP/LVET) plotted against left ventricular:aortic ratio $(L V: A o) .=$ Infants with patent ductus arteriosus, $\bigcirc=$ infants without patent ductus arteriosus $(n=44$. $r=0 \cdot 70, P E P / L V E T=0 \cdot 61-() \cdot 14 L V: A o)$.

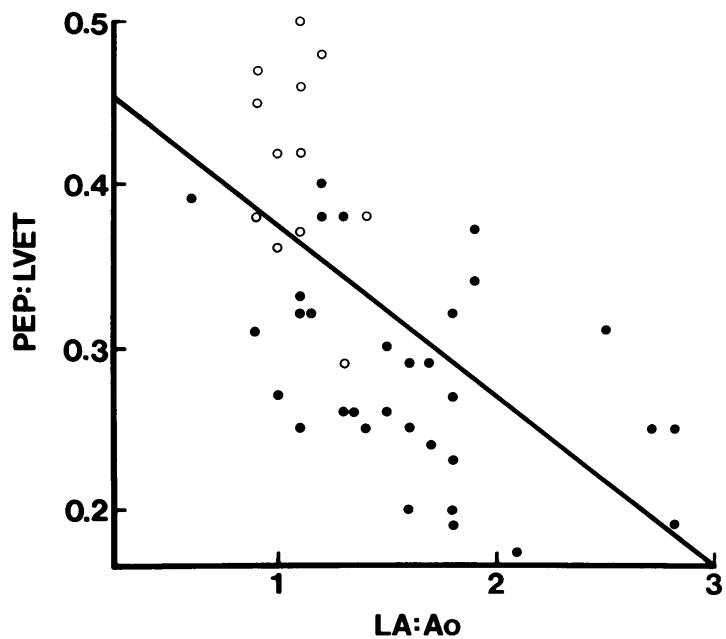

Fig. 4 Left pre-ejection period/left ventricular ejection time (PEP/LVET) plotted against left atrial:aortic ratio (LA:Ao). = Infants with patent ductus arteriosus, $\mathrm{O}=$ infants without patent ductus arteriosus $(n=44$, $r=0 \cdot 59, P E P / L V E T=0 \cdot 47-1 \cdot 10$ LA:Ao).

or left to right shunts through the ductus arteriosus. $^{6-8}$ It can detect a $5 \%$ right to left shunt. ${ }^{13}$ In this study the suprasternal notch approach was used. It was necessary to visualise contrast in either the transverse aortic arch or the right pulmonary artery or in both for the record to be considered 
satisfactory. Visualisation of contrast depends on catheter position, volume and rate of injection of contrast, and the rate of retrograde flow. Countercurrent injection has successfully been carried out through a radial artery cannula. ${ }^{14}$ Insufficient retrograde flow would be more likely to occur with a closed or narrow ductus arteriosus.

This study confirms the reports of preterm infants with PDA who did not have a murmur, including those with a large PDA in congestive heart failure ${ }^{5-9}$ Furthermore, individual $\mathrm{M}$ mode echocardiographic dimensions and systolic time intervals were found to be poor predictors of PDA. ${ }^{15-17}$ The sensitivity of $\mathrm{M}$ mode echocardiographic assessment of PDA was enhanced by combining several measurements. It has been shown that the left ventricle may be enlarged when the left atrial size is normal. ${ }^{18}$ The reduced systolic time intervals in PDA also makes it a useful variable in combination with dimensions. ${ }^{19-21}$ Left atrial and left ventricular enlargement occur either with an increased flow or with altered compliance or contractility. An infant with poor myocardial function would be expected to have an enlarged left ventricle and left atrium and may also have a murmur from atrioventricular valve regurgitation with $x$ ray appearances of cardiomegaly and pulmonary venous congestion. The systolic time interval, however, should help distinguish between such infants and those with PDA: with decreased contractility the PEP/LVET is increased but with PDA the preload increases and the afterload decreases, decreasing this ratio. In the present study there was a significant negative correlation between the left ventricular:aortic ratio and PEP/LVET, and these two measurements distinguished best between those with and without PDA. Our findings confirm that found in a study on infants with clinically apparent PDA, which showed that left heart dimensions combined with systolic time intervals gave the best discrimination between PDA and no PDA. ${ }^{20}$

In conclusion, clinical assessment is inadequate at detecting PDA early in the course in sick preterm infants. Contrast echocardiography is a safe and repeatable method of detecting PDA and documenting subsequent closure. Although previous studies reported a significant rate of reopening of the ductus arteriosus after apparent closure with treatment with indomethacin, the efficacy of indomethacin is better assessed objectively with contrast echocardiography. In one infant all variables returned to normal after treatment with indomethacin, although continuing duct patency was documented by contrast. Subsequently, clinical and $M$ mode echocardiographic signs of PDA reoccurred, and surgical ligation of the PDA was necessary. Objective and accurate methods of documenting PDA, such as with contrast echocardiography, are therefore required for assessing the true efficacy of treatment with indomethacin.

\section{References}

1 Jacob J, Gluck L. DiSessa T, et al. The contribution of PDA in the neonate with severe RDS. J Pediatr 1980;96:79-87.

2 Merritt TA, Harris JP, Roughmann K, et al. Early closure of the patent ductus arteriosus in very low birth weight infants: a controlled trial. J Pediatr 1981;99:281-6.

3 Mahony L, Carnero V, Brett C, Hymann MA, Clyman RI. Prophylactic indomethacin therapy for patent ductus arteriosus in very-low-birth-weight infants. N Engl J Med 1982;306:506-10.

${ }^{4}$ Gersony WM, Peckham GJ, Ellison RC, Miettinen OS, Nadas AS. Effects of indomethacin in premature infants with patent ductus arteriosus: results of a national collaborative study. J Pediatr 1983;102:895-906.

5 Thibeault DW, Emmanouilides GC, Nelson RJ, Lachman RS, Rosengart RM, Oh W. Patent ductus arteriosus complicating the respiratory distress syndrome in preterm infants. $J$ Pediatr 1975;86:120-6.

- Allen HD, Sahn DJ, Goldberg SJ. New serial contrast technique for assessment of left to right shunting patent ductus arteriosus in the neonate. Am J Cardiol 1978:41:288-94

7 Valdes-Cruz LM, Dudell GG. Specificity and accuracy of echocardiographic and clinical criteria for diagnosis of patent ductus arteriosus in fluid-restricted infants. J Pediatr 1981: 98:298-304.

${ }^{8}$ Zednikova M, Baylen BG, Yoshida Y, Emmanouilides GC. Precordial contrast echocardiographic detection of patent ductus arteriosus in small preterm infants. Pediatr Cardiol 1982:2:271-5.

" Vick GW, Satterwhite C, Cassady G, Philips J, Yester MV, Logic JR. Radionucleide angiography in the evaluation of ductal shunts in preterm infants. J Pediatr 1982:101:264-8.

11 Sahn DJ, DeMaria A, Kisslo J, Weyman A. Recommendations regarding quantitation in M-mode echocardiography: results of a survey of echocardiographic measurements. Circulation 1978;58:1072-82.

${ }^{11}$ Hirschfeld S, Meyer R, Schwartz DC, Korfhagen J, Kaplan S. Measurement of right and left ventricular systolic time intervals by echocardiography. Circulation 1975;51:304-9.

12 Sahn DJ, Allen HD, George W, Mason M. Goldberg SJ. The utility of contrast echocardiographic techniques in the care of critically ill infants with cardiac and pulmonary disease. Circulation 1977:56:959-68.

13 Pieroni DR, Varghese J, Freedom RM, Rowe RD. The sensitivity of contrast echocardiography in detecting intracardiac shunts. Cathet Cardiovasc Diagn 1979:5:19-29.

14 Elzenga NJ, Spritzer R. Countercurrent arterial contrast echocardiography in the assessment of left to right ductal shunting in preterm infants. Arch Dis Child 1984:59:533-6.

15 Silverman NH, Lewis AB, Heymann MA. Rudolph AM. Echocardiographic assessment of ductus arteriosus shunt in premature infants. Circulation 1974:50:821-5.

${ }^{16}$ Obeyesckere HI, Pankhurst S, Yu VYH. Pharmacological closure of ductus arteriosus in preterm infants using indomethacin. Arch Dis Child 1980;55:271-6.

17 Johnson GL, Desai NS. Cottrill CM. Johnson M, Noonan JA. Echocardiographic systolic time intervals in premature infants with patent ductus arteriosus. Pediatr Cardiol 1980;1:103-7.

${ }^{18}$ Hirschklau MJ, Disessa TG. Higgins CB, Friedman WF. Echocardiographic diagnosis: pitfalls in the premature infant with a large patent ductus arteriosus. J Pediatr 1978:92:474-7.

19 Bjorkhem GE. Lundstrom NR. Svenningsen NW. Influence of 


\section{Knight and $Y u$}

continuous positive airways pressure treatment on ductus arteriosus shunt assessed by echocardiography. Arch Dis Child 1977;52:659-61.

20 Johnson GL, Breart GL, Gewitz MH, et al. Echocardiographic characteristics of premature infants with patent ductus arteriosus. Pediatrics 1983:72:864-71.

21 Heitz F, Fouron J, vanDoesburg NH, et al. Value of systolic time intervals in the diagnosis of large patent ductus arteriosus in fluid-restricted and mechanically ventilated preterm infants. Pediatrics 1984;74:1069-74.

Correspondence to Dr V Y H Yu, Director of Neonatal Intensive Care, Queen Victoria Medical Centre, 172 Lonsdale Strect, Melbourne, Victoria 3000, Australia.

Received 3 January 1986 